\title{
Prognostic factors in primary malignant melanoma of the conjunctiva: a clinicopathological study of 256
} cases

\author{
A D A Paridaens, D C Minassian, A C E McCartney, J L Hungerford
}

\begin{abstract}
A series of 256 consecutive cases of invasive primary conjunctival malignant melanomas was examined to identify clinical and histopathological prognostic factors. The follow up period varied between 0.3 and 45.9 years (mean 9 years, median 6.3 years). The 5 year survival rate was estimated at $82.9 \%$, the 10 year survival rate at $69 \cdot 3 \%$. Multiple regression analysis with the Cox proportional hazards model was used to assess sex, age, and a number of baseline features of conjunctival malignant melanoma as possible prognostic factors influencing melanoma related mortality. In assessing each potential prognostic factor, the effects of all other factors were taken into account in the modelling process. Tumours in unfavourable locations - that is, those involving the palpebral conjunctiva, fornices, plica, caruncle, and lid margins, were associated with $2 \cdot 2$ times higher mortality compared with (epi)bulbar melanomas. Patients with mixed cell type tumours had about three times higher mortality compared with those with pure spindle cell melanomas, and histological evidence of lymphatic invasion by tumour cells was also a prognostic feature, carrying a fourfold increase in the death rate. Multifocal tumours were associated with a fivefold increase in mortality among those with tumours in favourable (epi)bulbar locations, but were not prognostic in patients with melanomas in unfavourable sites. The death rate was significantly higher in those with initial tumour thickness of more than $4 \mathrm{~mm}$, but only among patients with unfavourably located melanomas. Sex, age, and clinical origin of the tumour (primary acquired melanosis, pre-existing naevus, or de novo) were not useful prognostic indicators in this study.
\end{abstract}

(Br F Ophthalmol 1994; 78: 252-259)

Malignant melanoma of the conjunctiva is a potentially life threatening tumour involving the mucosa of the eye and eyelids. The natural history of this neoplasm has not been clearly established. Some melanomas present as a single pigmented nodule and never recur after local excision, some others arise from an area of flat conjunctival pigmentation which 'waxes and wanes" and often recur at other sites with varying time intervals. There has been only limited experience with the management of conjunctival melanoma, since this tumour is extremely rare, accounting for approximately $2 \%$ of eye malignancies. ${ }^{2}$
Several attempts have been made to identify prognostic factors for conjunctival melanoma. Such identification is important for tumour classification in individual cases, the choice of treatment, and the time of its implementation. ${ }^{3-11}$ Jacobiec $^{7}$ claimed that tumour thickness is the 'sovereign prognostic factor', but other authors ${ }^{3-6910} 12$ have suggested that the location, extension, multifocality, and mitotic rate may influence the outcome.

Possibly owing to the paucity of conjunctival melanomas, few reports on prognostic indicators for this neoplasm have excluded cases of in situ melanoma and primary acquired melanosis (PAM) with atypia or cases that were not histologically confirmed as malignant melanoma. In our attempt to analyse a prognostically more homogeneous group of tumours, we have studied a series of 256 patients with histologically invasive primary malignant melanomas of the conjunctiva that were treated and followed up in Moorfields Eye Hospital and St Bartholomew's Hospital between 1948 and 1991. A subset of 89 cases was reported in a previous follow up study by Jay. ${ }^{13}$ The large series of patients allowed for the use of multivariable analysis to assess the individual prognostic value of various putative risk factors in conjunctival melanoma.

\section{Patients, materials, and methods}

Clinical and pathological records of patients with a diagnosis of primary malignant melanoma of the conjunctiva that were treated in the ocular oncology clinics of Moorfields Eye Hospital and St Bartholomew's Hospital from 1948 until 1991 were reviewed. Additional clinical information on some of the earlier patients was gleaned from Jay's thesis. ${ }^{13}$ Only patients with a histological diagnosis of invasive malignant melanoma of the conjunctiva were included. Patients with a primary eyelid (cutaneous) melanoma were excluded. Histopathological biopsy and exenteration sections of the primary melanoma and subsequent recurrences were reviewed to verify the diagnosis of invasive conjunctival melanoma. In addition we assessed the site of the lesion, cell type, precursor lesion (naevus, PAM, or none (de novo)). On the basis of clinical observations and earlier reports ${ }^{3-691012}$ we defined (epi)bulbar and limbal locations as prognostically 'favourable' and other conjunctival locations, including the caruncle, plica, fornices, and palpebral conjunctiva, as 'unfavourable'. Furthermore, we measured the initial maximum tumour thickness and the maximum thickness of the thickest tumour in biopsy specimens taken throughout the course of the disease. We also 


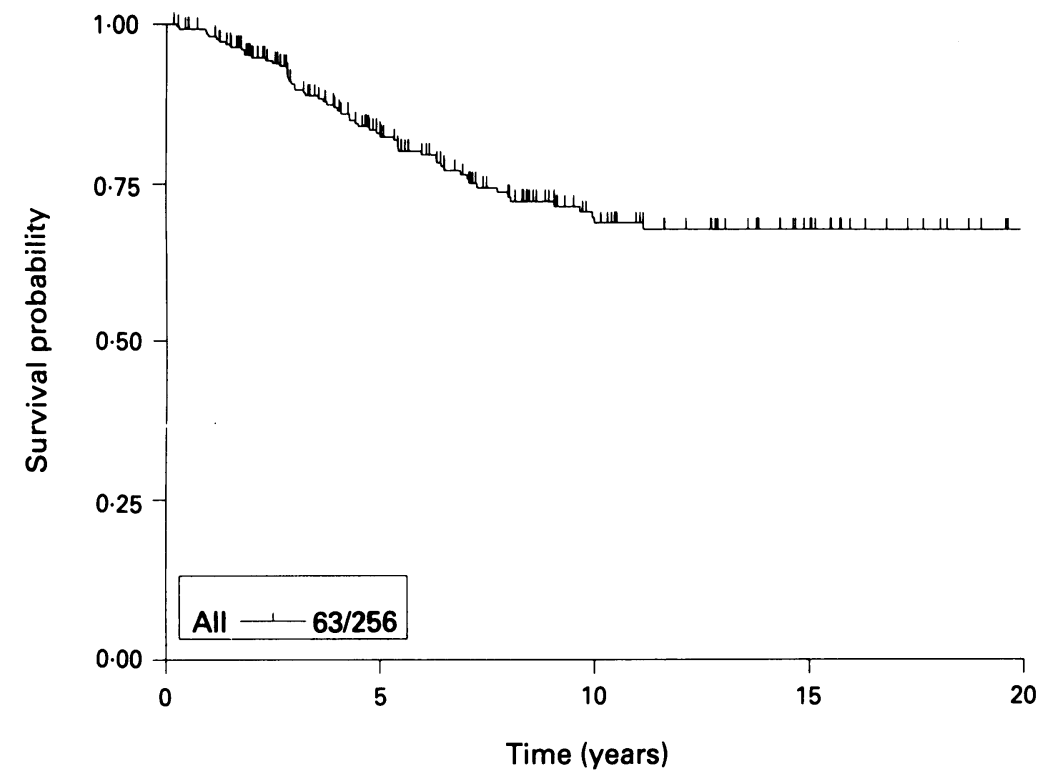

Figure 1 Kaplan-Meier survival curve for all 256 patients suffering from primary conjunctival malignant melanoma. of recurrence, secondary treatment, number of total times biopsied, adjuvant treatment $(\beta$ radiotherapy or cryotherapy), interval between diagnosis and exenteration, interval between diagnosis and last date of follow up, interval between exenteration and last date of follow up, outcome, cause of death, location of metastases (orbit, nasal cavity or paranasal sinuses, regional lymph nodes, distant sites), and whether primary or secondary exenteration was performed.

Clinical and pathological data were processed into tables using the Paradox database software from Borland International (UK) Ltd.

Statistical analysis, including Cox proportional hazards survival analysis and KaplanMeier estimation, was carried out using the epidemiological graphics, estimation, and testing (EGRET) software (Statistics and Epidemiology Research Corporation, Seattle, WA, USA). The Cox regression model allows for analysis of censored survival data adjusting for discrete as well as continuous covariates (possible prognostic factors), so that the influence on mortality of a single prognostic factor can be estimated after adjusting for effects of other prognostic factors. It is based on the exponential model: probability of survival to time $t=e^{-\phi t}$, where $\phi$ is the force of mortality or hazard rate. The larger the value of $\phi$, the faster the survival curve falls. The Cox model takes $\phi$ as a function of both time and covariates. The Kaplan-Meier survival curve shows the conditional probability of survival to year $t$, given that the patient survived to year $t-1$, It is not a simple unconditional probability of survival to year $t$ (proportion who survive to year $\mathrm{t}$ ), which would ignore the survival experience, during the earlier years, of those who have not been followed up to year $t$. The Kaplan-Meier survival curve gives a graphic summary of the survival experience of a cohort throughout the follow up period.

The following potential prognostic factors were assessed: sex, age, location and clinical origin of tumour, initial tumour thickness, multifocality, cell type, and lymphatic invasion. In assessing each prognostic factor, the effects of all other factors were taken into account in the modelling process.

\section{Results}

A total of 256 patients were included in the study. The follow up period from date of diagnosis to date last seen or date of death had a mean value of 9.0 years $(0.2-45.9$ years) and a median value of $6 \cdot 3$ years. The median follow up period for patients that died from metastatic melanoma was $4 \cdot 1$ years and other patients $7 \cdot 4$ years. In this study $153(59 \cdot 8 \%)$ survived the follow up period, $63(24.6 \%)$ died of metastatic melanoma, and 40 $(15 \cdot 6 \%)$ died of other causes (including other cancers).

Figure 1 shows the overall survival analysis according to the Kaplan-Meier method. The vertical stripes mark the end of follow up for each patient. The 5 year survival probability for all patients is estimated at $82.9 \%$ ( $95 \%$ confidence limits (CL) $77 \cdot 2-87 \cdot 3 \%$ ), the 10 year survival probability at $69 \cdot 6 \%$ (CL $62 \cdot 2-75 \cdot 9 \%$ ), and the

Figure 2 Age distribution of male and female patients in the study. 
Table 1 Clinical origin of tumour

\begin{tabular}{llllll}
\hline & De novo & Naevus & PAM & Unknown & All \\
\hline Males: & & & & & \\
$\quad$ Number & 25 & 22 & 53 & 3 & 103 \\
$\quad$ Row (\%) & 24.3 & 21.4 & 51.5 & 2.9 & \\
Females: & & & & & \\
$\quad$ Number & 32 & 24 & 94 & 3 & 153 \\
$\quad$ Row (\%) & 20.9 & 15.7 & 61.4 & 2.0 & \\
All: & & & & & \\
$\quad$ Number & 57 & 46 & 147 & 6 & 256 \\
Row (\%) & 22.3 & 18.0 & 57.4 & 2.3 & \\
\hline
\end{tabular}

PAM = primary acquired melanosis.

Table 2 Type of expression of tumour

\begin{tabular}{lclll}
\hline & Unifocal & Multifocal & Unknown & All \\
\hline Males & 72 & 30 & 1 & 103 \\
Row (\%) & $69 \cdot 9$ & $29 \cdot 1$ & $1 \cdot 0$ & \\
Females & 89 & 64 & 0 & 153 \\
Row (\%) & $58 \cdot 2$ & $41 \cdot 8$ & 0.0 & \\
All (\%) & 161 & 94 & 1 & 256 \\
Row (\%) & 62.9 & 36.7 & 0.4 & \\
\hline
\end{tabular}

15 and 20 year survival probabilities were both calculated as $67 \cdot 7 \%$ (CL 59.9-74.3\%).

There was no significant difference in outcome between patients who had been given treatment elsewhere before referral and those that were first seen in our oncology clinics.

\section{ASSESSMENT OF POSSIBLE PROGNOSTIC FACTORS}

\section{Sex}

Of the 256 patients included in the study, $40 \cdot 2 \%$ (103) were male and $59 \cdot 8 \%$ (153) female. The age distribution for males and females is shown in Figure 2.

Crude (unadjusted) analysis of the whole cohort of 256 patients show no significant difference in mortality rates between men and women $(\mathrm{p}=0 \cdot 35)$. Further analysis using the Cox proportional hazards model with adjustments for age, location and clinical origin of tumour, initial tumour thickness, cell type, unifocal or multi-

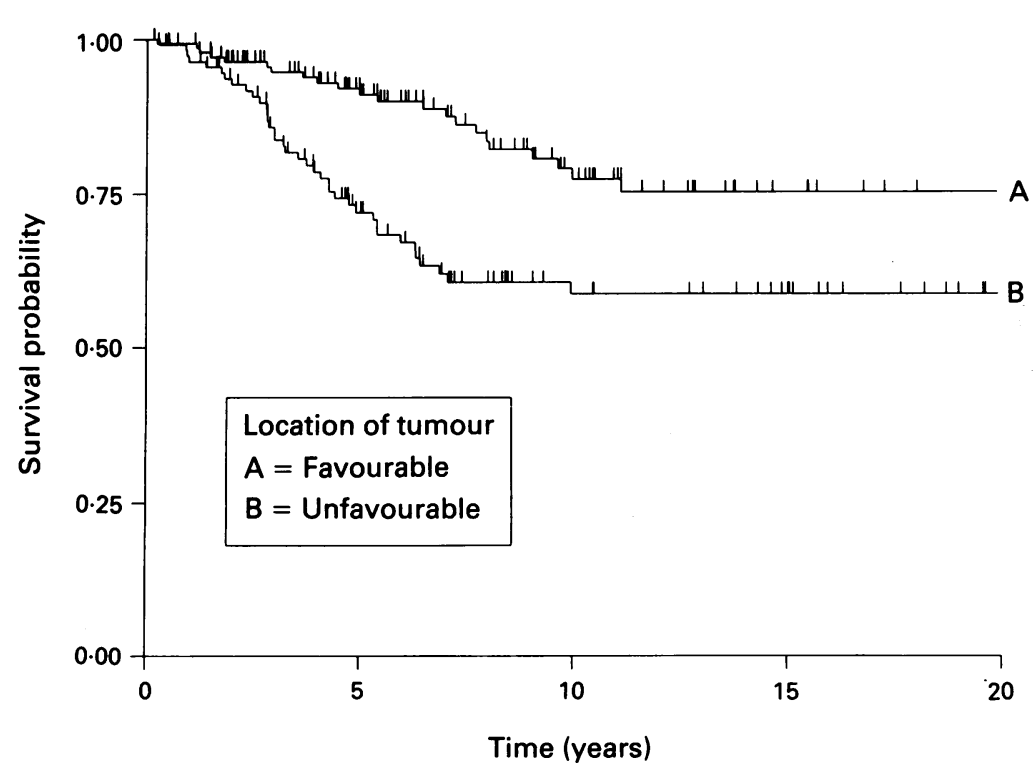

Figure 3 These Kaplan-Meier survival curves illustrate a significant difference in mortality between patients with (epi)bulbar melanomas (upper curve) and those with melanomas sited at the palpebral conjunctiva, the fornices, the caruncle, and plica (bottom curve) $(p=0.002)$.
Table 3 Location of tumour at first presentation

\begin{tabular}{lcc}
\hline & $\begin{array}{c}\text { Number of } \\
\text { patients }\end{array}$ & $\begin{array}{c}\% \text { of } \\
\text { total }\end{array}$ \\
\hline Favourable site: & 143 & $55 \cdot 9$ \\
Cornea & 27 & $10 \cdot 5$ \\
Corneolimbal & 163 & $63 \cdot 7$ \\
Bulbar conjunctiva $<2$ mm from lumbus & 76 & $29 \cdot 7$ \\
Bulbar conjunctiva $>2$ mm from lumbus & 59 & $23 \cdot 0$ \\
Unfavourable site: & 113 & $44 \cdot 1$ \\
Palpebral conjunctiva & 75 & $29 \cdot 3$ \\
Fornix & 67 & $26 \cdot 2$ \\
Caruncle & 33 & $12 \cdot 9$ \\
Plica & 18 & $7 \cdot 0$ \\
Eyelid & 29 & $11 \cdot 3$ \\
All sites: & 256 & \\
\hline
\end{tabular}

NB. The specific sites are not all exclusive - for example, fornix is included in palpebral conjunctiva.

focal tumours, and presence or absence of lymphatic invasion, show that the female/male death rate ratio (hazard ratio) is close to 1 (hazard ratio $=1 \cdot 16, p=0 \cdot 61)$. In the cohort of 113 patients with prognostically unfavourable tumour location, females had slightly higher (1.21 times higher) mortality than the males, but this difference was not significant $(p=0 \cdot 60)$.

The clinical origin of the melanoma in males and females is shown in Table 1. PAM was found more frequently in women, but this difference is not significant (Fisher's exact test: $p=0 \cdot 15$ ). The type of expression (multifocal versus unifocal) at diagnosis for males and females is displayed in Table 2. Multifocal melanoma occurred significantly more frequently in female patients $(42 \% v$ $29 \%$, Kruskal-Wallis exact test: $\mathrm{p}=0.048$ ).

Tumours at unfavourable sites were seen in $45 \cdot 6 \%(47)$ of men and in $43 \cdot 1 \%(66)$ of women. The difference between sexes was not significant (Kruskal-Wallis exact test: $p=0 \cdot 70$ ). Tumour recurrence involving favourable sites was seen in $54.4 \%(56)$ of male and in $56.9 \%$ (87) of female patients.

There was one case in which hormonal influence was suspected: a young woman developed recurrent conjunctival melanomas over the course of three subsequent pregnancies.

Age

In the whole cohort, age at diagnosis is not a significant prognostic factor when the other factors are adjusted for, but there is a tendency towards higher mortality in the older age group (>69 years). The hazard ratios compared with the youngest age group are: 0.76 for $30-49$ age group ( $p=0.63), 1 \cdot 14$ for $50-69$ age group $(p=$ 0.81 ), and 1.46 for the oldest age group $(\mathrm{p}=0.53)$. This trend of higher mortality with increasing age is absent in the cohort of patients with unfavourable tumour location, where all age groups experience similar survival. However, in the cohort of 143 patients with favourable location, the trend is more marked but still not significant. In this cohort, the hazard ratios for the two oldest age groups are $5 \cdot 26(p=0 \cdot 15)$ and $9.04(p=0.08)$ respectively, all compared with the youngest age group (Cox multivariable model, Table 5).

In $151(59 \%)$ cases there was evidence of PAM, 
Table 4 Site of recurrence of tumour

\begin{tabular}{lllllll}
\hline & \multicolumn{2}{l}{$\begin{array}{l}\text { Favourable } \\
\text { location }\end{array}$} & & \multicolumn{2}{l}{$\begin{array}{l}\text { Unfavourable } \\
\text { location }\end{array}$} & \\
\cline { 2 - 3 } $\begin{array}{l}\text { Location of tumour } \\
\text { at first presentation }\end{array}$ & Number & $\%$ & & Number & $\%$ & All \\
\hline Favourable location & 56 & $90 \cdot 3$ & 6 & $9 \cdot 7$ & 62 \\
Unfavourable location $\dagger$ & 2 & $6 \cdot 1$ & 31 & 93.9 & 33 \\
$\quad$ & 58 & $61 \cdot 1$ & 37 & 38.9 & 95 \\
\hline
\end{tabular}

$\star$ Corneal, corneolimbal, and bulbar conjunctival tumours. †Tumours involving the palpebral conjunctiva, fornix, caruncle, or plica.

while this precursor was not found in $102(40 \%)$ cases. In three $(1 \%)$ cases the biopsy specimen consisted of tumour only, which precluded assessment of the presence of PAM. In four cases of amelanotic multicentric melanoma, there was histopathological evidence of an amelanotic intraepithelial precursor, the so-called acquired melanosis 'sine pigmento'. ${ }^{14}$ In five cases there was evidence of a naevus and PAM, a combination of precursor lesions which has been reported earlier. ${ }^{8}$

Crude (unadjusted) analysis of the whole cohort shows that malignant melanomas arising from PAM are associated with a worse prognosis $(p=0.002)$ compared with those originating spontaneously (de novo) or from a pre-existing naevus. However, when adjustment is made for tumour location and/or histological cell type, the association disappears. Similarly, there is no significant association between clinical origin of tumour and mortality in the cohort of 143 patients with favourable tumour locations. However, in the group of 113 patients with unfavourable tumour location, those with melanomas arising from PAM have an estimated $2 \cdot 1$ times higher mortality compared with naevus or de novo origins $(\mathrm{p}=0 \cdot 18$, Table 5$)$.

\section{Location of tumour}

The site of involvement at the time of diagnosis is shown in Table 3: 113 patients (44\%) had melanomas that involved an unfavourable site, including the palpebral conjunctiva, fornix, caruncle, plica, and eyelid.

Kaplan-Meier survival curves for patients with conjunctival melanomas in favourable locations and for those with tumours in unfavourable locations are compared in Figure 3. The curves differ significantly $(p=0.002)$. The 5 and 10 year survival probabilities are $92.0 \%$ and $79 \%$ respectively for the 'favourable' group, and $72.0 \%$ and $58.7 \%$ for the 'unfavourable' group.

Further multiple regression analysis using the Cox model shows that patients with unfavourable tumour location have a significantly higher mortality rate $(2 \cdot 18$ times higher, $\mathrm{p}=0.004)$ compared with those with favourable tumour locations.

Table 4 shows the involvement of unfavourable sites during the course of the disease in patients with prognostically favourable and unfavourable site at first presentation.

\section{Initial thickness of tumour}

Initial thickness of tumour is also significantly associated with survival (Table 5). However, the model identified a significant interaction between tumour thickness and tumour location, indicating that the effect of tumour thickness on survival depends upon location of the tumour. This finding forces analysis of the 'favourable' and 'unfavourable' groups separately, as the effect of tumour thickness on survival is different in the two groups.

Multiple regression analysis of the cohort of 143 patients with favourable tumour location shows that tumour thickness is not associated with mortality $(\mathrm{p}=0.78$, hazard ratio 0.76 for $>4$ $\mathrm{mm}$ thickness) when adjustment is made for effects of age, sex, and the other factors. In this cohort there were very few $(n=7)$ with initial tumour thickness of more than $4 \mathrm{~mm}$.

Table 5 Assessment of sex, age, and baseline features of malignant melanoma of the conjunctiva as prognostic factors, influencing survival. The results from multivariable Cox proportional hazards regression models are summarised. In assessing each potential prognostic factor, the effects of all the other factors have been taken into account. The reported hazard ratios give the death rate ratio in the groups being compared. For example, the hazard ratio of $2 \cdot 18$ for 'tumour location' indicates that patients with unfavourable tumour locations have about two times higher melanoma related mortality compared with those with favourable location

\begin{tabular}{|c|c|c|c|c|c|c|}
\hline \multirow[b]{2}{*}{ Potential prognostic factors } & \multicolumn{2}{|c|}{ Whole cohort: 256 patients } & \multicolumn{2}{|c|}{$\begin{array}{l}113 \text { Patients with unfavourable } \\
\text { tumour location }\end{array}$} & \multicolumn{2}{|c|}{$\begin{array}{l}143 \text { Patients with favourable } \\
\text { tumour location }\end{array}$} \\
\hline & $\begin{array}{l}\text { Hazard ratio } \\
(95 \% C L)\end{array}$ & p Value & $\begin{array}{l}\text { Hazard ratio } \\
(95 \% C L)\end{array}$ & $p$ Value & $\begin{array}{l}\text { Hazard ratio } \\
(95 \% C L)\end{array}$ & $p$ Value \\
\hline \multicolumn{7}{|l|}{ Sex: } \\
\hline Females $v$ males & $1 \cdot 16(0 \cdot 7-2 \cdot 0)$ & 0.610 & $1 \cdot 21(0 \cdot 6-2 \cdot 5)$ & $0 \cdot 596$ & $0 \cdot 93(0 \cdot 3-2 \cdot 5)$ & $0 \cdot 892$ \\
\hline $\begin{array}{l}\text { Age: } \\
<30 \text { (referent) }\end{array}$ & & & & & & \\
\hline $\begin{aligned} 30-49 v & <30 \\
50-69 v & <30 \\
70+v & <30\end{aligned}$ & $\begin{array}{l}0 \cdot 76(0 \cdot 2-2 \cdot 4) \\
1 \cdot 14(0 \cdot 4-3 \cdot 4) \\
1 \cdot 46(0 \cdot 5-4 \cdot 7)\end{array}$ & $\begin{array}{l}0.629 \\
0.807 \\
0.527\end{array}$ & $\begin{array}{l}0.82(0 \cdot 2-3 \cdot 2) \\
0 \cdot 76(0 \cdot 2-2 \cdot 7) \\
0.82(0 \cdot 2-3 \cdot 5)\end{array}$ & $\begin{array}{l}0.772 \\
0.671 \\
0.786\end{array}$ & $\begin{array}{l}2 \cdot 03(0 \cdot 2-22) \\
5 \cdot 26(0 \cdot 5-51) \\
9 \cdot 04(0 \cdot 8-102)\end{array}$ & $\begin{array}{l}0.563 \\
0.152 \\
0.075\end{array}$ \\
\hline Tumour location: & & & & & & \\
\hline $\begin{array}{l}\text { Unfavourable } v \text { favourable } \\
\text { Clinical origin: }\end{array}$ & $2 \cdot 18(1 \cdot 3-3 \cdot 7)$ & 0.004 & & & & \\
\hline $\begin{array}{l}\text { PAM } v \text { others } \\
\text { Initial tumour thickness: }\end{array}$ & $1 \cdot 16(0 \cdot 6-2 \cdot 3)$ & 0.673 & $2 \cdot 12(0 \cdot 7-6 \cdot 3)$ & $0 \cdot 177$ & $0.62(0.2-1 \cdot 9)$ & $0 \cdot 394$ \\
\hline $\begin{aligned} 1-4 \mathrm{~mm} v & <1 \mathrm{~mm} \\
>4 \mathrm{~mm} v & <1 \mathrm{~mm}\end{aligned}$ & $\begin{array}{l}1 \cdot 14(0 \cdot 6-2 \cdot 2) \\
2 \cdot 30(1 \cdot 0-5 \cdot 4)\end{array}$ & $\begin{array}{l}0 \cdot 702 \\
0.055\end{array}$ & $\begin{array}{l}2 \cdot 33(0 \cdot 7-8 \cdot 0) \\
3 \cdot 87(1 \cdot 01-15)\end{array}$ & $\begin{array}{l}0 \cdot 179 \\
0 \cdot 048\end{array}$ & $\begin{array}{l}0 \cdot 67(0 \cdot 3-1 \cdot 6) \\
0 \cdot 76(0 \cdot 1-5 \cdot 4)\end{array}$ & $\begin{array}{l}0 \cdot 375 \\
0 \cdot 780\end{array}$ \\
\hline $\begin{array}{l}\text { Multifocality: } \\
\text { Multifocal } v \text { unifocal }\end{array}$ & & & & & & \\
\hline $\begin{array}{l}\text { Multifocal } v \text { unifocal } \\
\text { Cell type: }\end{array}$ & $1 \cdot 54(0 \cdot 7-3 \cdot 2)$ & $0 \cdot 241$ & $0.85(0 \cdot 3-2 \cdot 2)$ & $0 \cdot 727$ & $5 \cdot 22(1 \cdot 3-21)$ & 0.023 \\
\hline $\begin{array}{l}\text { Epithelioid and mixed } v \text { pure } \\
\text { spindle cell }\end{array}$ & $2 \cdot 91(1 \cdot 3-6 \cdot 6)$ & $0 \cdot 010$ & $2 \cdot 40(0 \cdot 8-7 \cdot 0)$ & $0 \cdot 110$ & $4 \cdot 67(1 \cdot 3-17)$ & 0.021 \\
\hline $\begin{array}{l}\text { Pympent } v \text { absent } \\
\text { Present }\end{array}$ & $4 \cdot 01(2 \cdot 2-7 \cdot 4)$ & $<0.001$ & $2 \cdot 10(0 \cdot 8-5 \cdot 6)$ & $0 \cdot 135$ & $8 \cdot 84(3 \cdot 3-23)$ & $<0.001$ \\
\hline
\end{tabular}

PAM = primary acquired melanosis . 


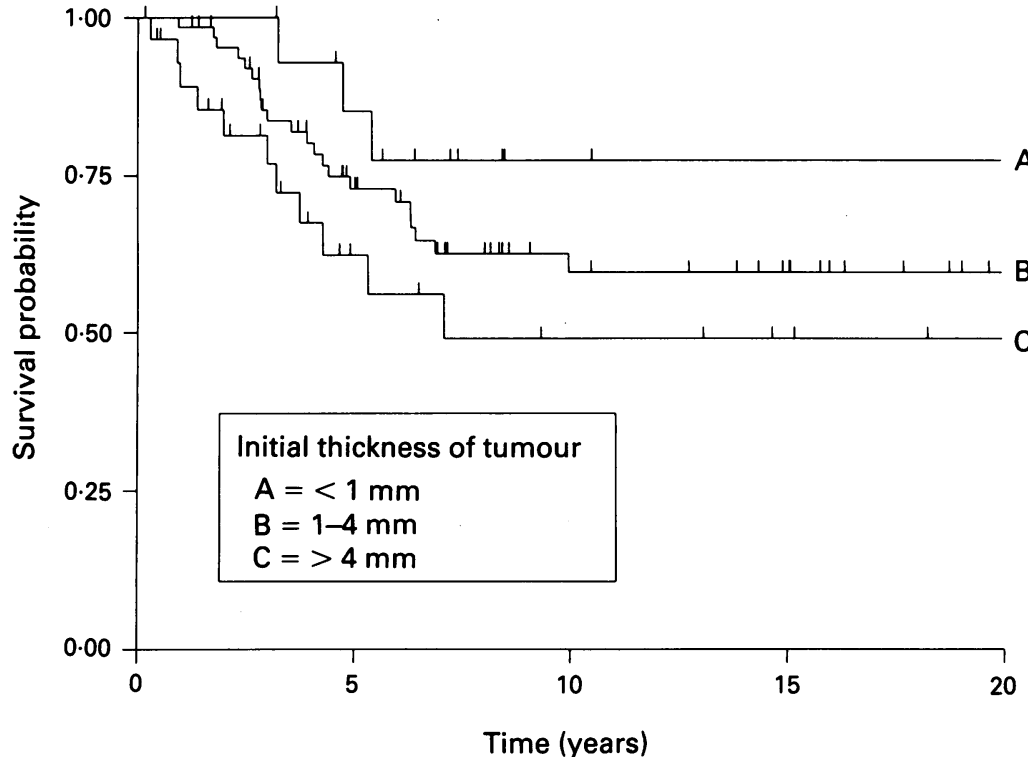

Figure 4 Kaplan-Meier survival curves showing an adverse influence of tumour thickness (measured at the time of entry into the study) on survival probability in the cohort of 113 patients with conjunctival malignant melanomas sited at adverse melanomas sited at adverse
sites. Patients with initial tumour thickness greater than $4 \mathrm{~mm}$ have $3 \cdot 87$ times higher death rate compared with those with tumour thickness of less than $1 \mathrm{~mm}(p=$ 0.048)

Figure 5 Kaplan-Meier survival analysis of 256 patients with conjunctival melanoma, showing increased melanoma related mortality in the group of tumours with pure epithelioid and mixed cell types $(n=$ 195) compared with the group of spindle cell melanomas $(n=58)$. In three patients the cell type was not identified.

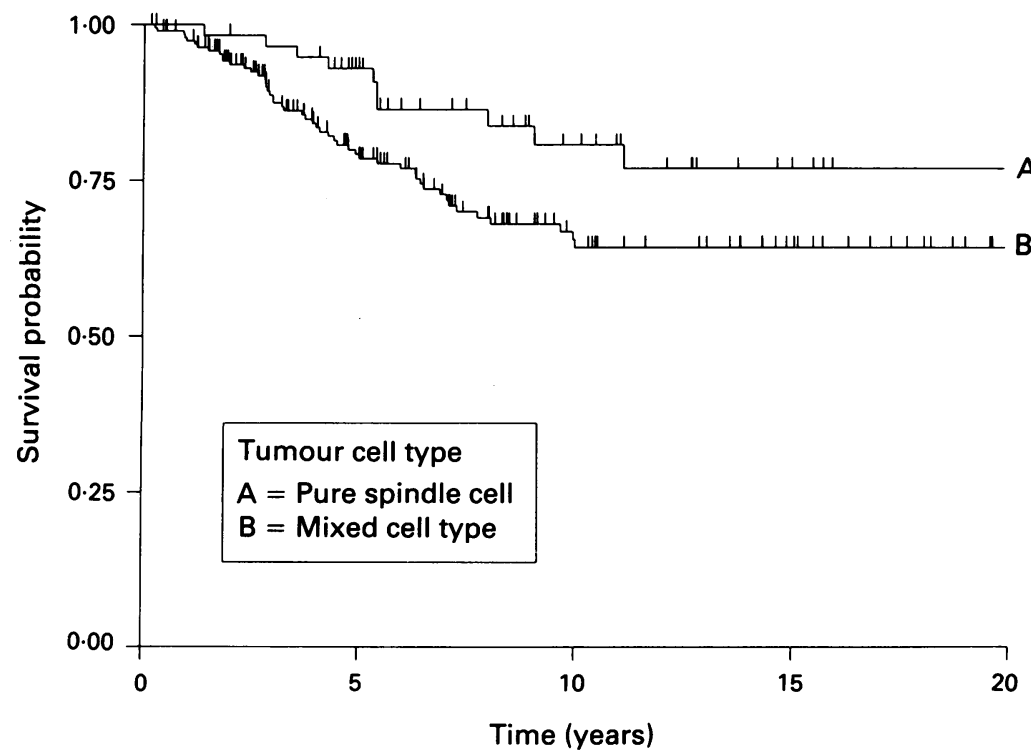
significant $(p=0 \cdot 18)$ The Kaplan-Meier survival curves are shown in Figure 4.

\section{Multifocality}

Unadjusted analysis of the whole cohort shows that patients with multifocal tumours have significantly higher mortality compared with those with unifocal malignant melanomas $(p=$ 0.007 ). However, when adjustment is made for tumour location, the observed association disappears. This is largely due to the fact that $73 / 94$ (78\%) of multifocal tumours versus only $39 / 161$ (24\%) of unifocal tumours are situated at prog0.048 ) Patients with of less than $1 \mathrm{~mm}$ ( $\mathrm{p}$ mm have 2.33 times higher mortality than the nostically unfavourable locations. However, the picture is more complex since the prognostic effect of multifocal tumours may be minimal or absent in the 'unfavourable' group but significant in the 'favourable' cohort, so that these two cohorts need to be looked at separately. When the cohort of patients with favourable tumour location are analysed separately, patients with multifocal tumours have $5 \cdot 22$ times greater death rate compared with those with unifocal tumours $(p=0.023$, Table 5). By contrast, in the 'unfavourable' cohort multifocal tumours are not associated with higher mortality (hazard ratio $0.85, \mathrm{p}=0.73$ ).

\section{Cell type}

Analysis of the whole cohort shows that patients with pure epithelioid and mixed cell types have 2.91 times higher mortality $(\mathrm{p}=0.01)$, compared with those with pure spindle cell tumours, but the magnitude of this effect may depend upon tumour thickness. The data are not sufficiently large to allow further detailed exploration of this phenomenon. The Kaplan-Meier curve is shown in Figure 5.

Similarly, in the 'favourable' cohort, patients with epithelioid and mixed cell type melanomas have 4.67 times higher mortality compared with those with pure spindle cell tumours $(\mathrm{p}=0.021)$. In the 'unfavourable' group the association is weaker and not significant (hazard ratio $2 \cdot 40$, $p=0 \cdot 11)$.

\section{Lymphatic invasion}

In the whole cohort, patients with evidence of lymphatic invasion have an estimated 4.01 times higher death rate compared with those with no evidence of such invasion ( $p<0.001$, Cox multivariable model). The Kaplan-Meier survival curves are shown in Figure 6. In the 'favourable' group, patients with evidence of lymphatic invasion have 8.84 times higher mortality compared with those with no evidence of lymphatic invasion $(p<0.001$, Cox multivariable model). In the 'unfavourable' cohort, the hazard ratio for lymphatic invasion is $2 \cdot 1(\mathrm{p}=0 \cdot 13)$. There is no evidence of heterogeneity of effect across the two cohorts, so the more stable estimate for the whole cohort of 256 may be more useful.

OTHER CHARACTERISTICS OF THE STUDY COHORT The right eye was involved in $40.6 \%(n=104)$, the left eye in $50.0 \%(n=128)$, and in $9.8 \%(n=$ 24 ) the laterality was not recorded. Bilateral disease was not noted.

A total of 81 patients were treated between 1948 and 1960, 85 were treated between 1960 and 1980, and 90 between 1980 and 1991; 160 $(62.5 \%)$ patients received no previous treatment elsewhere, $67(26 \cdot 2 \%)$ subjects had a history of one treatment in another centre, and $29(11.3 \%)$ subjects had received two or more earlier treatments, mostly excisional biopsies. One patient had been given 15 treatments, including excision biopsies and adjuvant radiotherapy, before referral to Moorfields Eye Hospital.

The mean number of biopsies in our patient 


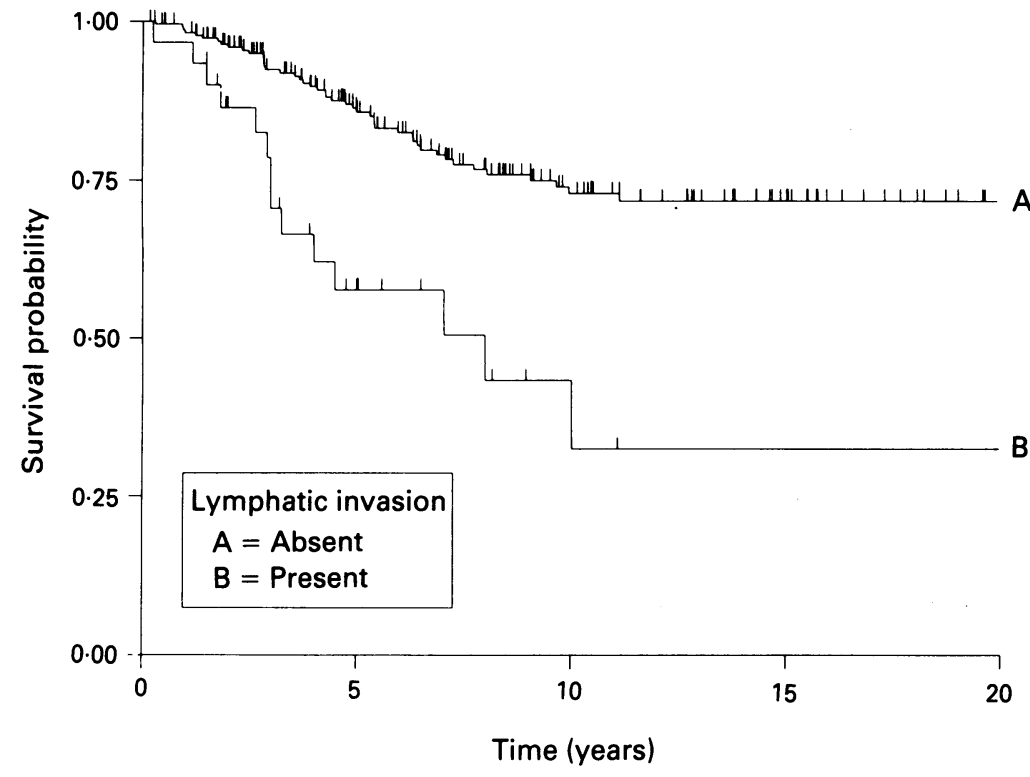

Figure 6 Lymphatic invasion was detected in 30 patients with conjunctival melanoma. Fifteen of those patients died of metastatic melanoma. Lymphatic invasion was not seen in 226 patients; 48 of those died of metastatic disease. This difference in survival probability is reflected in the Kaplan-Meier curves and is highly significant $(p<0.001)$. found in this study. With the exception of conjunctival melanomas, mucosal melanomas have a tendency to fare worse than melanomas arising in the skin, which has been explained by the complex lymph drainage system in the oral and nasal mucosa. ${ }^{19}$ In the present study we have examined various clinicopathological factors that may influence the outcome of patients with conjunctival melanoma.

\section{THICKNESS OF TUMOUR}

Cutaneous melanoma is a relatively common tumour and has been well documented. The thickness of this neoplasm has been found to correlate with survival by Breslow et al. ${ }^{20}$ Silvers et $a l^{21}$ applied Breslow's quantitative technique for measuring tumour thickness to their selection of 28 invasive conjunctival melanomas and found that a thickness of $1.8 \mathrm{~mm}$ best separated low from high risk tumours. Folberg et $a l^{8}$ confirmed that the thickness of the patient's thickest lesion correlates with prognosis for patients who have melanomas arising from an area of primary acquired melanosis (PAM), but found a lesser figure of $0.8 \mathrm{~mm}$. Interestingly, they found no significant association between tumour thickness of the initial biopsies and prognosis of their group of 98 patients with conjunctival melanomas arising from PAM. Although we found the initial tumour thickness to be correlated with mortality, the effect of tumour thickness on survival seems to depend upon location of the tumour. cedure. One patient, who had had severa excision biopsies of recurrent limbal melanomas, developed a black cornea due to melanocytic infiltration and was treated by corneoscleral lamellar keratoplasty. ${ }^{15}$

Recurrent disease was absent in $115(44.9 \%)$ patients. In $69(27 \cdot 0 \%)$ patients the melanoma recurred at the previous site, and in $72(28 \cdot 1 \%)$ a recurrent focus of tumour was detected at a new site. Regional lymphadenopathy was noted in 29 $(11 \cdot 3 \%)$ patients. In $102(39 \cdot 8 \%)$ this finding was negative, while in 125 cases $(48 \cdot 8 \%)$ no clinical information on lymph node involvement during the follow up period was available. In 14 (5.5\%) patients there was evidence of orbital recurrence. Three of these patients also developed metastases in the ipsilateral nasal cavity and paranasal sinuses. There were eight $(3 \cdot 1 \%)$ cases of documented involvement of the nasal cavity and paranasal sinuses, a subset of whom was reported earlier. ${ }^{16} 17$ There was one unusual case of nasal and orbital recurrence of conjunctival melanoma 21 years after orbital exenteration. ${ }^{17}$

\section{Discussion}

In general, patients suffering from a malignant melanoma of the conjunctiva have better prospects for survival compared with those who have mucosal melanomas at other sites. Melanomas arising in the mucosa of the nasal cavity and paranasal sinuses often grow large before being detected and treated, which results in a 5 year survival probability of less than $30 \% .{ }^{18}$ The early detection and prompt treatment of the majority of conjunctival melanomas may partially explain the $83 \% 5$ year survival probability which was

\section{LOCATION OF TUMOUR}

Compared with epibulbar melanomas, melanomas involving the palpebral conjunctiva, the fornices, and caruncle have been associated with a higher rate of metastatic death, especially when they are multifocal. ${ }^{3-6912}$ Fuchs et $a l^{9}$ found the site of the primary melanoma to be most closely related to high metastatic risk, which was confirmed by De Wolff-Rouendaal in a survey of conjunctival melanoma in the Netherlands. ${ }^{22}$ In our study it was demonstrated by multiple regression analysis (which took into account the confounding effects of other factors) that the site of the primary lesion is one of the most important prognostic factors. Caruncular melanomas seem to form an especially treacherous class of tumours, which may be partly explained by the fact that the caruncle is a skin derivative and has a different anatomy compared with conjunctiva. The presence of pigmentation of the eyelid margin in association with conjunctival melanoma was shown to be an ominous sign, even when the eyelid does not harbour malignant melanocytes. ${ }^{23}$

\section{MULTIFOCALITY}

This study showed a significantly worsened outcome for patients with multifocal melanomas compared with those with unifocal tumours. However, this effect was not noticeable in the cohort of melanomas involving prognostically unfavourable sites, which suggests the stronger influence of adverse site on prognosis. 


\section{GROWTH PATTERN}

The growth pattern of melanomas has also been reported to be of prognostic importance. Patients with either cutaneous or conjunctival melanomas that grow vertically rather than horizontally fare worse. ${ }^{24}$ Tumours with a predominant vertical growth pattern are invasive at an early stage, are thicker, and therefore consequently associated with an unfavourable prognosis. Folberg et $a l^{8}$ found that pagetoid epithelial invasion of melanocytes in conjunctival melanomas with PAM was a sensitive indicator of subsequent metastasis. Other significant histological risk factors detected by these authors included paucity of small polyhedral cells and cellular atypia in first lesions and presence of an in situ growth pattern and lack of inflammation in the invasive component in the thickest lesions of melanomas arising from PAM. Fuchs $e t a^{9}$ studied a group of 26 conjunctival melanomas in their search for histopathological risk factors. They found no obvious relation between mitotic rate, the amount of inflammatory infiltrate, the cell type, or the presence of adjacent intraepithelial involvement to outcome, but the number of cases they studied may have been too limited to detect such influence. In a previous study from this database, ${ }^{25}$ we linked the counting of argyrophilic nucleolar organising regions (AgNORs) in the nuclei of silver stained sections of conjunctival malignant melanoma to survival but we were unable to show any prognostic significance.

CELL TYPE

In uveal melanomas the histological cell type is regarded as an important prognostic indicator. Individuals suffering from epithelioid cell uveal melanoma are at greater risk than those that develop a melanoma composed of spindle cells. ${ }^{26}$ This has not been found to be true in skin melanoma, ${ }^{27}$ while in conjunctival melanoma the influence of cell type has been underexplored. This study showed that among patients with 'favourable' tumour location, those suffering from melanomas with pure epithelioid and mixed cell types have a $4 \cdot 7$ times greater risk of metastatic death compared with those with pure spindle cell melanomas. Again, in the cohort of patients with tumours at adverse sites, this effect is moderated by the influence of location on prognosis.

\section{LYMPHATIC INVASION}

Microscopic invasion of tumour cells into lymph and blood vessels has proved to be of prognostic significance for skin melanoma, ${ }^{28}$ but there has been no large scale study to investigate the influence of lymphatic or vascular invasion of melanocytes on the survival of patients suffering from conjunctival melanoma. In this study we found a 4.0 times greater chance of metastatic death in patients with histopathological evidence of lymphatic invasion compared with those without. This phenomenon was observed in patients with melanomas growing at both favourable and unfavourable areas of the conjunctiva.

\section{CLINICAL ORIGIN}

Reese $^{1}$ found that melanomas arising from naevi had a worse prognosis compared with those arising de novo or from an area of acquired melanosis, which is in sharp contrast to the findings of Jay ${ }^{3}$ and Liesegang and Campbell. ${ }^{29}$ None of these studies, however, corrected for other potential prognostic factors, such as anatomical location, histological thickness, and multifocality of the melanoma. This study showed that in the group of patients with unfavourable melanomas, the patients with melanomas originating from PAM have an estimated $2 \cdot 1$ times greater mortality compared with those with tumours arising de novo or from a naevus. Interestingly, the presence of PAM was not associated with higher mortality in patients with (epi)bulbar and limbal tumours.

SEX

We found an overall 3:2 female/male ratio of the subjects in our study. Ash ${ }^{30}$ and Jacobiec ${ }^{31}$ also found a higher prevalence of conjunctival melanoma in women. In our study, however, the overall survival was not influenced by the sex of the patient suffering from this tumour.

\section{AGE}

In his study of 19 cases of malignant melanoma of the conjunctiva, Crawford ${ }^{4}$ claimed that younger patients who develop this neoplasm have a worsened prognosis. In contrast, De WolffRouendaal $^{22}$ thought that young age of the patient seems to be a favourable factor in relation to outcome. In the present study only the $70+$ age group fared worse than other age groups. This may be partly explained by the decreasing immune system activity in elderly people. The latter mechanism has also been implicated in the pathogenesis of tumours occurring during pregnancy.

\section{HORMONES}

Hormonal influence of the melanoma - for example, by oestrogens, is another distinct possibility. We encountered one example of a young woman who showed growth of conjunctival melanosis and melanoma over the course of three subsequent pregnancies. Although oestrogen receptors have been detected in conjunctival melanoma using monoclonal antibodies to ER-D5 antigen, ${ }^{32}$ these were not detected in this unusual case. Jay ${ }^{313}$ reported another woman aged 22 years who developed a limbal melanoma during pregnancy.

In general, one of the problems encountered in the statistical analysis of prognostic factors for malignant tumours is the variation in 'lead times' of some of these factors between patients at the time of entry into the study. For example, at the time of diagnosis one patient may have had a $5 \mathrm{~mm}$ tumour for 5 years, while another may have suffered from a similar size tumour for only 3 months. This difference in lead time may result in a different outcome. Therefore, some factors for example, tumour thickness and lymphatic invasion, should be treated as time dependent 
variables. Also, during the follow up the status of the patient and the melanoma may alter. For example, a simple epibulbar nodule at diagnosis may have changed into a multinodular thick melanoma involving multiple sites in several months. Ideally, the analysis should take into account these variations in tumour status, but it is often impractical or impossible to assess whether or when a certain factor has changed. Crawford ${ }^{4}$ and Folberg $e t a^{8}$ pointed out that the prognostic factors of both the primary melanoma and the recurrences should be taken into account to predict the outcome. Also, orbital exenteration and other clinical interventions, and the time of their implementation, may have an effect on the course of the disease.

Some series studying malignant melanoma of the conjunctiva included lesions with a histological diagnosis of 'melanoma in situ' or 'PAM with atypia'. In our study such lesions were excluded, since not all of these intraepithelial tumours invade into the deeper layers containing lymphatic and blood vessels with the subsequent risk of metastases. Also, within the group of melanocytic tumours that invade the subepithelial space, the time interval between histological diagnosis and invasion varies and cannot be predicted.

This study showed that the outcome within the group of invasive melanomas is importantly determined by the site involved. While patients with (epi)bulbar melanomas have a $92 \% 5$ year survival probability, those with melanomas involving other conjunctival sites have only a $72 \%$ chance of surviving 5 years following diagnosis of their tumour. Factors that vary from one location to another and that may underlie this phenomenon include the density of lymphatic and blood vessels and ultrastructural barriers to cellular invasion such as scleral tissue and Bowman's membrane. Also, the relative exposure and ease of the visibility of conjunctival sites is likely to be important for early detection and treatment. The latter mechanism may be relevant for tumours in the fornices, but does not explain the worsened prognosis for patients with visible melanomas sited at the caruncle. This study also showed that evidence of lymphatic invasion in biopsy specimens signified a greater risk of metastasis and subsequent death. Therefore, special attention with regard to such tumour spread should be paid by the examining pathologist. Other prognostic factors include cell type, tumour thickness, and multifocality. Sex and age of the patient and clinical origin of the melanoma were not found to be of prognostic value.

We thank Miss Golfo Chrysanthopolou who kindly supported us with the clinical records, that are kept at Moorfields Eye Hospital with the clinical records, that are kept at Moorfields Eye Hospital. Fischer-Strichting, Utrecht, The Netherlands.
1 Reese AB. Precancerous and cancerous melanosis. In: Boniuk M, ed. Ocular and adnexal tumors. St Louis: Mosby, 1964: 19-23.

2 Char DH. The management of lid and conjunctival malignancies. Surv Ophthalmol 1980; 24: 679-89.

3 Jay B. Naevi and melanomata of the conjunctiva. $B r f$ Ophthalmol 1965; 49: 169-204.

4 Crawford JB. Conjunctival melanomas: prognostic factors. A review and an analysis of a series. Trans Am Ophthalmol Soc 1980; 78: 467-502.

5 Silvers DN, Jakobiec FA, Freeman TR, Lefkowitch JH, Elie RC. Melanoma of the conjunctiva: a clinicopathologic study. In: Jakobiec FA, ed. Ocular and adnexal tumors. Birmingham, AL: Aesculapius, 1978: 583-99.

6 Jeffrey IJM, Lucas DR, McEwan C, Lee WR. Malignant melanoma of the conjunctiva. Histopathology 1986 ; 10: 36378 .

7 Jacobiec FA. Conjunctival melanoma. Unfinished business. Arch Ophthalmol 1980; 98: 1378-84.

8 Folberg R, McLean IW, Zimmerman LE. Malignant melanoma of the conjunctiva. Hum Pathol 1985b; 16: 13643.

9 Fuchs U, Kivela T, Liesto K, Tarkkanen A. Prognosis of conjunctival melanomas in relation to histopathological features. Br 7 Cancer 1989; 59: 261-7.

10 Stefani FH. A prognostic index for patients with malignant melanoma of the conjunctiva. Graefes Arch Clin Exp Ophthalmol 1986b; 224: 580-2.

11 Lommatzsch PK, Lommatzsch RE, Kirsch I, Fuhrmann P. Therapeutic outcome of patients suffering from malignant melanomas of the conjunctiva. Br $\mathcal{F}$ Ophthalmol 1990; 74 615-9.

12 Zimmerman LE. The histogenesis of conjunctival melanomas In: Jakobiec FA, ed. Ocular and adnexal tumors. Birmingham, AL: Aesculapius, 1978: 572-82.

13 Jay B. Naevi and melanomata of the conjunctiva. Thesis presented to Cambridge University for the degree of $\mathrm{MD}$ 1964

14 Paridaens ADA, McCartney ACE, Hungerford JL. Multifocal amelanotic conjunctival melanoma and acquired melanosi sine pigmento. Brf Ophthalmol 1992; 76: 163-5.

15 Paridaens ADA, Kirkness CM, Garner A, Hungerford JL. Recurrent malignant melanoma of the corneal stroma: a case of 'black cornea'. Br f Ophthalmol 1992; 76: 444-6.

16 Robertson DM, Hungerford JL, McCartney ACE. Malignan melanomas of the conjunctiva, nasal cavity, and paranasal sinuses. Am $\mathcal{F}$ Ophthalmol 1989; 108: 440-2.

17 Paridaens ADA, McCartney ACE, Lavelle RJ, Hungerford JL. Nasal and orbital recurrence of conjunctival melanoma 21 years after exenteration. Br F Ophthalmol 1992; 76: 36921 year.

18 Lund V. Malignant melanoma of the nasal cavity and paranasal sinuses. F Laryngol Otol 1982; 96: 347.

19 Conley J, Pack GT. Melanoma of the mucous membranes of the head and neck. Arch Ophthalmol 1974; 99: 315-9.

20 Breslow A. Thickness, cross-sectional areas and depth of invasion in the prognosis of cutaneous melanoma. Ann Surg 1970; 172: 902-8.

21 Silvers DN, Jakobiec FA, Freeman TR, Leskowitch JH, Elie RC. Melanoma of the conjunctiva: a clinicopathological study. In: Jakobiec FA, ed. Ocular and adnexal tumours. Birmingham, AL: Aesculapius, 1978: 582-99.

22 Wolff-Rouendaal D de. Conjunctival melanoma in the Netherlands: a clinico-pathological and follow-up study Thesis presented to University of Leiden, 1990

23 Robertson DM, Hungerford JL, McCartney ACE. Pigmentation of the eyelid margin accompanying conjunctival melanoma. Am F Ophthalmol 1989; 108: 435-9.

24 Bernardino VB Jr, Naidoff MA, Clark WH Jr. Malignant melanomas of the conjunctiva. Am $\mathcal{F}$ Ophthalmol 1976; 82: 383-94.

25 Paridaens ADA, Seregard S, Minassian D, Hungerford JL, McCartney ACE. AgNOR counts in conjunctival malignant melanoma lack prognostic value. $\mathrm{Br} \mathcal{F}$ Ophthalmol 1992; 76 621-3.

26 Davidorf FH, Lang JR. The natural history of melanoma of the choroid: small versus large tumors. Ophthalmology 1975 79: $310-20$.

27 McGovern V, Shaw H, Milton G, Farago GA. Prognostic significance of the histological features of malignant significance of the histological features

28 Grove AS Jr. Melanomas of the conjunctiva. Int Ophthalmol Clin 1980; 20: 161-75.

29 Liesegang TJ, Campbell RJ. Mayo clinic experience with conjunctival melanomas. Arch Ophthalmol 1980; 98: 1385-9. 30 Ash JE. Epibulbar tumors. Am f Ophthalmol 1950; 33: 120319.

31 Jakobiec FA, Rini FJ, Fraunfelder FT, Brownstein S Cryotherapy for conjunctival primary acquired melanosis and malignant melanoma. Ophthalmology 1988; 95: 105870 .

32 Paridaens DA, Alexander RA, Hungerford JL, McCartney ACE. Oestrogen receptors in conjunctival malignant melanoma: immunocytochemical study using formalin fixed paraffin wax sections. F Clin Pathol 1991; 44: 840-3. 